\title{
Impact of Pycnogenol on Acetaminophen-Induced Hepatorenal Damage
}

\author{
Mehmet Mahir Fersahoğlu ${ }^{(\mathbb{D})}$, Erkan Özkan 2(D), Ayliz Velioğlu-Öğünç ${ }^{3(\mathbb{D})}$, Serkan Sayıner ${ }^{4(\mathbb{D})}$, Feriha \\ Ercan ${ }^{5(\mathbb{D})}$, Özlem Tuğçe Çilingir Kaya ${ }^{5 \mathbb{D}}$, Ahmet Özer Şehirli ${ }^{6 * *(\mathbb{D})}$
}

1 Department General Surgery, Fatih Sultan Mehmet Education and Research Hospital, Istanbul, Turkey; drfersahoglu@hotmail.com (M.M.F.);

2 Department of General Surgery, Istanbul Haydarpasa Numune Education and Research Hospital, Istanbul, Turkey; dr.erkan@mynet.com (E.O.);

3 Vocational School of Health Related Professions, Marmara University, Istanbul, Turkey; aylizvelioglu@gmail.com (A.V.O.);

4 Department of Biochemistry, Faculty of Veterinary Medicine, Near East University, 99138 Nicosia, Northern Cyprus, Mersin 10, Turkey; serkan.sayiner@neu.edu.tr (S.S.);

5 Department of Histology \& Embryology, School of Medicine, Marmara University, Istanbul, Turkey; fercan@marmara.edu.tr; tugce.cilingir@marmara.edu.tr (O.T.C.K.);

6 Department of Pharmacology, Faculty of Dentistry, Near East University, 99138 Nicosia, Northern Cyprus, Mersin 10, Turkey; ahmetozer.sehirli@neu.edu.tr (A.Ö.Ş.);

* Correspondence: ahmetozer.sehirli@neu.edu.tr (A.Ö.Ş.);

Scopus Author ID 6603160775

Received: 13.10.2021; Revised: 15.11.2021; Accepted: 18.11.2021; Published: 5.12.2021

Abstract: We investigated the protective effects of pycnogenol (PYC), a natural anti-oxidant with an anti-inflammatory effect, on the acetaminophen (APAP)-induced hepatorenal injury in rats. Wistar albino rats were divided into four experimental groups: control, PYC (10 mg/kg, ip), APAP (1000 $\mathrm{mg} / \mathrm{kg}$ ), and APAP+PYC groups. Rats were decapitated 24 hours after the APAP injection, and their blood was taken to determine blood urea nitrogen (BUN), creatinine, aspartate aminotransferase (AST), alanine aminotransferase (ALT), and pro-inflammatory cytokines; TNF- $\alpha$ and IL-1 $\beta$. Liver and kidney tissue samples were obtained for the histological examination and the determination of malondialdehyde (MDA) and glutathione (GSH) levels as well as myeloperoxidase (MPO) and $\mathrm{Na}^{+} / \mathrm{K}^{+}$ATPase activities. PYC treatment decreased the APAP-induced elevations in serum pro-inflammatory cytokines and reduced the impairment of liver and kidney functions. Furthermore, the increase in tissue lipid peroxidation and myeloperoxidase activity and the decrease in the GSH levels and $\mathrm{Na}^{+} / \mathrm{K}^{+}$-ATPase activity by the APAP overdose were reversed by the PYC treatment. Besides, histologic findings reinforce the protective effect of PYC in APAP-induced hepatorenal damage. PYC, which appears to have restored the GSH and depressed neutrophil infiltration and the associated release of proinflammatory cytokines, merits consideration as an anti-oxidant and anti-inflammatory agent in preventing APAP-induced hepatorenal damage.

Keywords: acetaminophen; pycnogenol; lipid peroxidation; glutathione; cytokine.

(C) 2021 by the authors. This article is an open-access article distributed under the terms and conditions of the Creative Commons Attribution (CC BY) license (https://creativecommons.org/licenses/by/4.0/).

\section{Introduction}

Acetaminophen (APAP), also known as paracetamol, is a broadly utilized antipyretic and pain-relieving pharmaceutical and considered safe at therapeutic doses. Single or repeated high-dose APAP administration is known to cause toxicity, resulting in glutathione depletion (a cellular anti-oxidant) and an increase in neutrophil infiltration. Thus, APAP has been 
reported to involve the pathophysiology of renal and hepatic injury in animal and human experiments [1,2]. The primary treatment approach against APAP toxicity is the administration of anti-oxidant agents such as $\mathrm{N}$-acetylcysteine, which in principle provides an enhanced cellular glutathione concentration [3].

Naturally, various plants contain compounds of the flavonoid group, and these compounds possess cytoprotective effects [4,5]. One of these compounds is Pycnogenol (PYC), which resembles a bioflavonoid composition and is extracted through a process involving ethanol and water. The PYC mixture primarily consists of cinnamic or phenolic acids, polyphenolic monomers, and glycoside derivatives [6,7]. PYC has been previously noted to have ameliorative effects on inflammation [7], viral infections [8], skin elasticity [9], cognitive [10], and cardiovascular problems [11]. To date, it has been stated that all agents are responsible for the bioactivity of this agent $[7,8,12]$. These effects have been reported to occur mainly through radical scavenging activity $-[10,13]$. Besides, PYC has also been demonstrated to reduce levels of various pro-inflammatory mediators [14]. Sehirli et al. [15] have established that PYC is protective against ischemia-reperfusion renal injury.

Rats are frequently preferred in animal experiments of tissue injury due to structural and functional similarities to human beings $[15,16]$. Thus, rats were chosen as the model animal for this study. This study aimed (i) to answer the question of whether high-dose APAP induced hepatorenal damage caused an alteration of the biochemical profile, pro-inflammatory cytokines, and oxidant-antioxidant parameters, and (ii) to consider the ameliorative effect of treatment with PYC in experimentally hepatorenal injury.

\section{Materials and Methods}

\subsection{Animals and ethical approval.}

The experimental studies were permitted by Animal Ethics Committee (Approval No: 67.2010 mar). A total of thirty-two 200-250 g Wistar albino rats, including both sexes, were adapted to laboratory conditions $\left(+22 \pm 2{ }^{\circ} \mathrm{C}, \% 50-60\right.$ humidity, rat cages (4 rats/cage) with cage area $\left(350 \mathrm{~cm}^{2}\right)$ with 12-hour light-dark cycles and without any restrictions to the availability of their standard rat chow and water. The laboratory and statistical analysts were blinded to the groups and the administration protocols allocated to the rats.

\subsection{Experimental procedures.}

The rats were allocated into 4groups, 8 animals in each group $(n=8)$ as follows: control, PYC (10 mg/kg, intraperitoneal [15]), APAP (APAP $1000 \mathrm{mg} / \mathrm{kg}$, intraperitoneal [17] and APAP+PYC (APAP $1000 \mathrm{mg} / \mathrm{kg}$; PYC $10 \mathrm{mg} / \mathrm{kg}$ intraperitoneal) groups. The rats were euthanized twenty-four hours after APAP injection. Blood, hepatic and renal tissue samples were collected from each animal.

\subsection{Detection of hepatic and renal injury.}

Alanine aminotransferase (ALT) and Aspartate aminotransferase (AST) enzyme activities, indicators of hepatocellular injury, were determined in blood samples. Besides, Blood urea nitrogen (BUN) and creatinine (Crea) levels were assessed regarding the renal injury. Test parameters were performed using an automated analyzer and routine assay kits. 
2.4. Measurement of serum concentration of inflammatory cytokines.

Tumour necrosis factor- $\alpha$ (TNF- $\alpha$ ) and Interleukin-1 $\beta$ (IL-1 $\beta)$, indicators of inflammation, were quantified in blood samples using commercially available immunoassay test kits (BioSource Europe S.A., Nivelles, Belgium).

\subsection{Determination of hepatic and renal MDA and GSH levels.}

Tissue samples were homogenized in ice-cold $\mathrm{KCl}(150 \mathrm{mM})$ to measure liver and kidney malondialdehyde (MDA) and glutathione (GSH) levels, thus assessing oxidation and anti-oxidant status $[18,19]$. MDA levels were measured using the previously described method [20] and expressed in nmol MDA/g tissue. GSH levels were assessed utilizing Ellman's reagent [21]. The GSH results were expressed in $\mu \mathrm{mol} \mathrm{GSH} / \mathrm{g}$ tissue.

\subsection{Measurement of hepatic and renal Myeloperoxidase and $\mathrm{Na}+/ \mathrm{K}+-A T P a s e$ activities.}

Myeloperoxidase (MPO), as a marker of neutrophil infiltration [22], was determined from the tissue samples. A previously reported method by Hillegass et al. [23] was performed to measure MPO activity, and the results were expressed as U MPO/g tissue. $\mathrm{Na}^{+} / \mathrm{K}^{+}$-ATPase activity, as an indicator of oxidative membrane damage, was determined by quantifying the release of inorganic phosphate from ATP, as documented earlier [24]. Accordingly, tissue homogenates were added to ATPase buffer and ouabain to quantify the total ATPase activity and $\mathrm{Mg}^{2+}$-ATPase activity, respectively. Then, $\mathrm{Na}^{+} / \mathrm{K}^{+}$-ATPase activity was calculated using an equation: total ATPase activity minus $\mathrm{Mg}^{2+}$-ATPase activity and was expressed as nmol $\mathrm{P}_{\mathrm{i}} / \mathrm{mg}$ protein/h. The method described by Lowry et al. [25] was performed to detect the protein concentration of the tissue samples.

\subsection{Histological examination.}

Hepatic and renal tissue samples were fixed in $10 \%$ formaldehyde. Then, tissue samples were processed routinely for embedding in paraffin wax. Paraffin sections ( $5 \mu \mathrm{m}$ thick) were stained using hematoxylin and eosin (H\&E) and evaluated histopathologically. To assess histopathological alterations, experienced histologists (OTC and FE), who were blinded to the experimental procedures, examined all tissue sections under a light microscope (Olympus BX51, Tokyo, Japan).

\subsection{Statistical analyses.}

Data were analyzed using GraphPad Software (San Diego, CA, USA), Prism 6.0. The one-way analysis of variance (ANOVA) was computed for the statistical evaluation of data, and Tukey's posthoc test was used for binary comparison. The data were expressed as mean \pm SEM. The $\mathrm{p}<0.05$ was considered statistically significant.

\section{Results and Discussion}

Following APAP administration, BUN and creatinine levels and AST and ALT activities were statistically higher in APAP group than the control group, while all levels significantly declined in the APAP+PYC group (Table 1). Inflammatory cytokines, TNF- $\alpha$ and $\mathrm{IL}-1 \beta$, were significantly higher in the APAP group compared to the control group $(\mathrm{p}<0.001$; 
Figure 1). In contrast, PYC significantly promoted a decline in cytokine levels in the APAP+PYC group ( $<<0.01-0.001$; Figure 1).

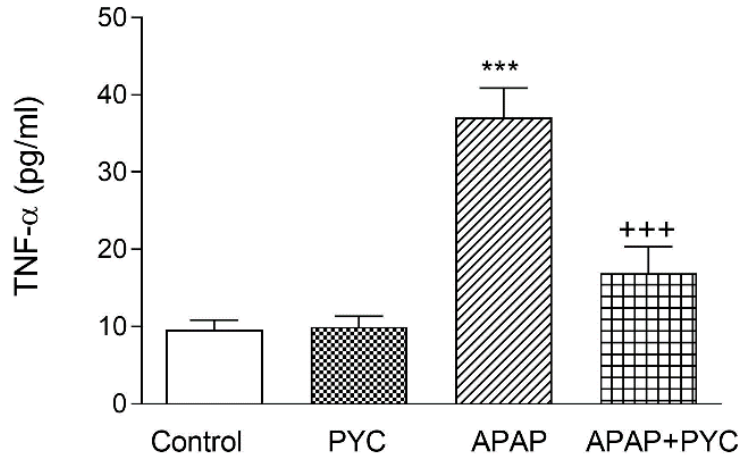

(a)

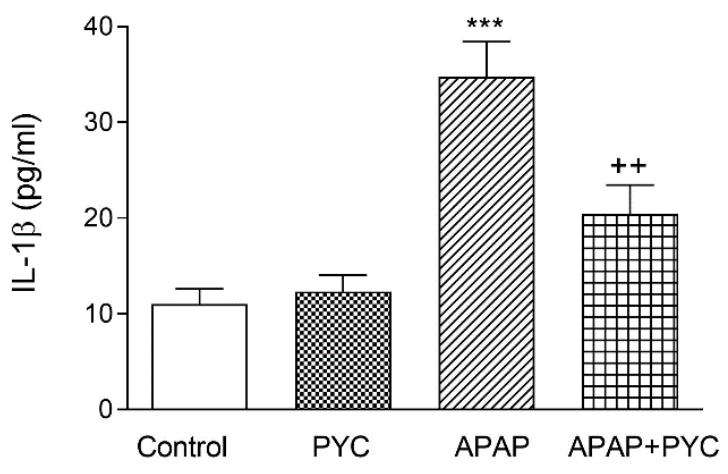

(b)

Figure 1. Serum (a) TNF- $\alpha$ and (b) IL- $1 \beta$ concentrations of the experimental groups. *** $p<0.001$ APAP versus control group; ++ $\mathrm{p}<0.01$ and $+++\mathrm{p}<0.001 \mathrm{APAP}+\mathrm{PYC}$ versus APAP group.

Table 1. Serum Aspartate aminotransferase (AST), Alanine aminotransferase (ALT), Blood urea nitrogen (BUN), and creatinine levels of the experimental groups $(n=8$; mean \pm SEM). PYC: Pycnogenol; APAP: Acetaminophen.

\begin{tabular}{|c|c|c|c|c|}
\hline & Control & PYC & APAP & APAP+PYC \\
\hline AST (U/L) & $92.3 \pm 8.2$ & $81 . \pm 12.3$ & $248.3 \pm 18.7 * * *$ & $125.5 \pm 18.9 *,+++$ \\
\hline ALT (U/L) & $47.1 \pm 3.9$ & $48.3 \pm 5.3$ & $80.1 \pm 7.9 * *$ & $51.5 \pm 5.7+$ \\
\hline BUN (U/L) & $23.5 \pm 2.2$ & $24.7 \pm 1.7$ & $41.8 \pm 7.9 *$ & $31.3 \pm 2.9$ \\
\hline Creatinine (U/L) & $0.42 \pm 0.04$ & $0.41 \pm 0.04$ & $1.18 \pm 0.12 * * *$ & $0.78 \pm 0.12 *+$ \\
\hline
\end{tabular}

Hepatorenal injury caused by drugs has been linked to reactive oxygen species and mitochondrial dysfunction during drug metabolism [26,27]. Tissue damage associated with oxidative stress may trigger and/or suppress various signaling pathways [28]. A study has shown that subtoxic APAP doses make hepatocytes responsive to the cytotoxic effects of TNF$\alpha$ [29]. On the other hand, a powerful pro-inflammatory cytokine, IL-1 $\beta$, is known to increase during APAP toxicity [30-32]. The presented study results have demonstrated that significant elevations in serum TNF- $\alpha$ and IL- $1 \beta$ concentrations with high dose APAP were in parallel with the literature [33]. The effects of bioflavonoids extracted from Pinus maritima on proinflammatory cytokines have been examined previously, and PYC was reported to decrease the synthesis of IL-1 $\beta$ levels $[15,31,34]$. In this study, PYC treatment reversed the APAP-induced cytokine elevations parallel with the literature.

Despite APAP-induced hepatotoxicity having been described in-depth in the literature as the most common clinical observation after toxicity, the extrahepatic findings of APAP toxicity have not been fully discussed. It is known that APAP-induced renal toxication is the second most common clinical observation and is related to the oxidation process of APAP [35,36]. Similarly, Akakpo et al. [36] showed that APAP toxicity in extrahepatic tissues such as the kidney was at least partly due to liver-derived APAP metabolites. In the light of this knowledge, we investigated the APAP-induced toxicity not only in the liver but also in the kidney tissues.

Hepatocellular changes induced by APAP are identified by significant elevations in ALT and AST activities [37,38]. In this study, APAP caused significant increases in ALT and AST activities, while PYC treatment reduced both ALT and AST. Thus, PYC treatment is 
thought to be involved in defense against cellular injury. Similarly, creatinine and BUN levels elevated in the APAP groups and significantly declined in the APAP+PYC group.

APAP administration significantly raised hepatic and renal MDA concentrations in the APAP group compared to the control group ( $\mathrm{p}<0.01-0.001$; Figure 2). Contrarily, PYC treatment decreased hepatic and renal MDA levels in the APAP+PYC group compared to the APAP group ( $p<0.01-0.001$; Figure 2). GSH levels in the liver and kidney declined significantly in the APAP group compared to the control group $(\mathrm{p}<0.01$ for each; Figure 3$)$. In the APAP+PYC group, this decline was reversed, and GSH values were significantly elevated $(\mathrm{p}<0.05$; Figure 3$)$.

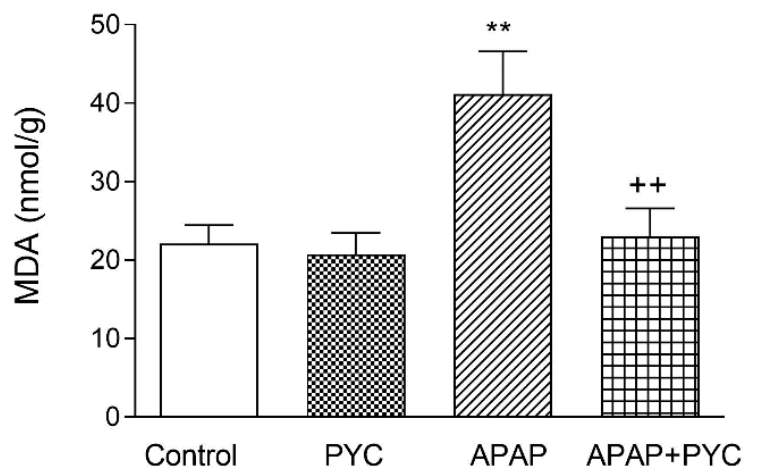

(a)

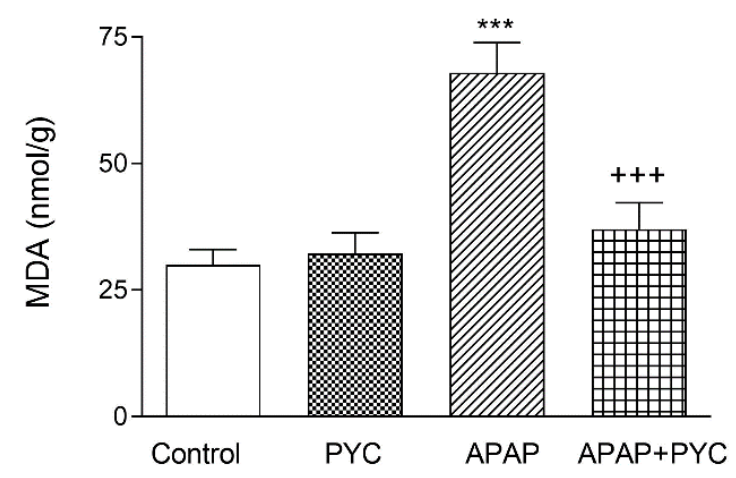

(b)

Figure 2. (a) Hepatic and (b) renal tissue malondialdehyde (MDA) values of the experimental groups. ** $\mathrm{p}<0.01$ and $* * * \mathrm{p}<0.001$ APAP versus control group; $++\mathrm{p}<0.01$ and $+++\mathrm{p}<0.001$ APAP+PYC versus APAP group.

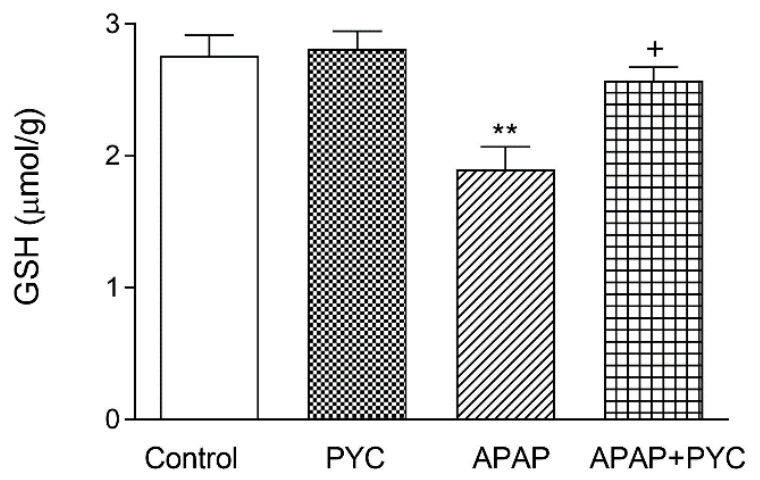

(a)

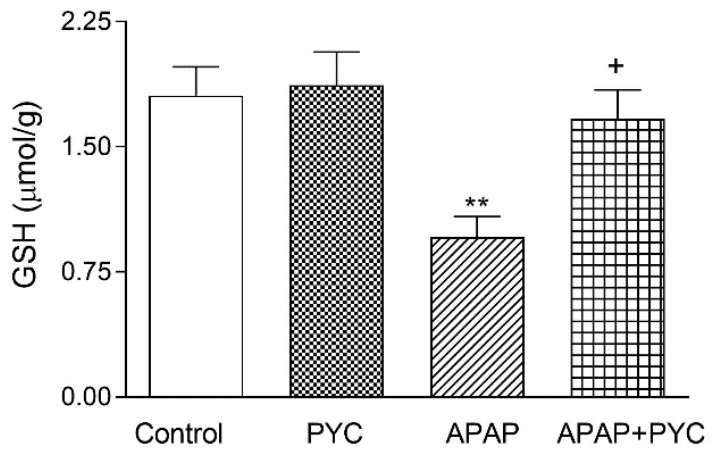

(b)

Figure 3. (a) Hepatic and (b) renal tissue glutathione (GSH) levels of the experimental groups. **p<0.01 APAP versus control group; $+\mathrm{p}<0.05$ APAP+PYC versus APAP group.

GSH, which is ubiquitous in all cell types, is a powerful non-enzymatic anti-oxidant and regulates intracellular redox homeostasis [39]. Cellular GSH depletion in hepatic cells has been detected to participate in APAP toxicity [40]. High doses of APAP cause GSH depletion, possibly causing irreversible deterioration of cellular proteins and thus hepatic necrosis [41]. Therefore, the intracellular GSH level is the primary marker of oxidative damage. The result of the presented study revealed that hepatic and renal GSH levels declined significantly. Lipid peroxidation has been demonstrated to increase the rate of APAP toxicity [17,42] by causing a structural modification of cellular lipid-protein complexes [43]. MDA is a significant marker of lipid peroxidation [44]. The presented study has revealed that MDA levels increased 
significantly in both tissues as a result of oxidative damage caused by APAP after GSH depletion. Nevertheless, PYC treatment reversed these effects and protected the tissues against histologically confirmed oxidative stress, and previous studies have found it to be a powerful anti-oxidant. [45,46]. In particular, it has been suggested that PYC has healing properties against a variety of free radical-mediated degenerative conditions, such as diabetes [47], ethanol-induced cell death [48], and ischemia/reperfusion injury [15,49].

Hepatic and renal MPO levels in the APAP group were significantly higher than in the control groups ( $\mathrm{p}<0.001$; Figure 4). However, in the APAP+PYC group, there was a significant decline in MPO activity compared to the APAP group due to the PYC treatment $(\mathrm{p}<0.05-0.001$; Figure 4). $\mathrm{Na}^{+} / \mathrm{K}^{+}$-ATPase activities of both tissue samples were significantly lower in the APAP group than in the control groups $(\mathrm{p}<0.05$; Figure 5). Furthermore, PYC treatment effectively shifted $\mathrm{Na}^{+} / \mathrm{K}^{+}$-ATPase activities back in liver and kidney tissues compared to the APAP group ( $\mathrm{p}<0.05$, Figure 5).

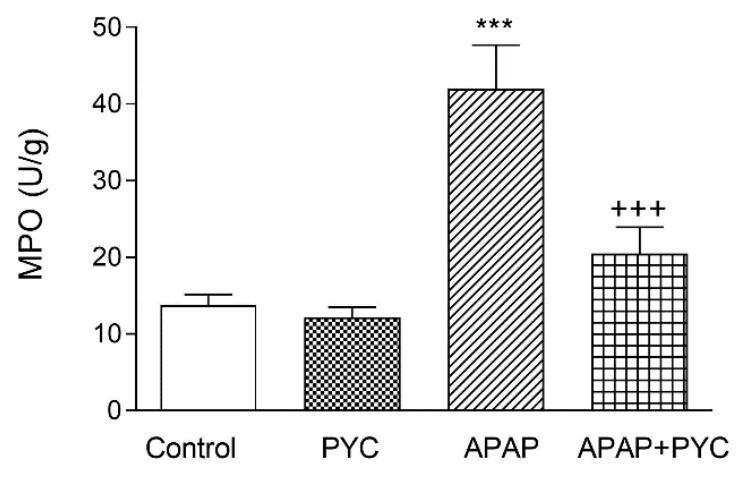

(a)

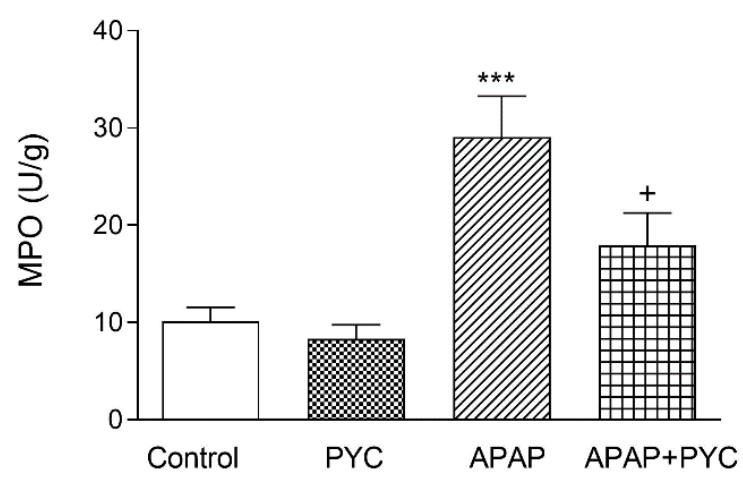

(b)

Figure 4. (a) Hepatic and (b) renal tissue myeloperoxidase (MPO) activities of the experimental groups. *** $\mathrm{p}<0.001$ APAP versus control group; $+\mathrm{p}<0.05$ and $+++\mathrm{p}<0.001$ APAP $+\mathrm{PYC}$ versus APAP group.

Neutrophils are essential members of the innate immune system, and vital for human life, as they defend against invading microorganisms, tissue traumas, or any inflammatory signal [50]. However, activated neutrophil adhesion to the endothelium, producing high reactive oxygen species (ROS), and protease secretion such as MPO, create the potential to cause tissue damage. MPO is a critical enzyme required for neutrophil activity. Various stimulants activate neutrophils to release MPO. Thus, MPO is a marker of neutrophil infiltration [51,52].

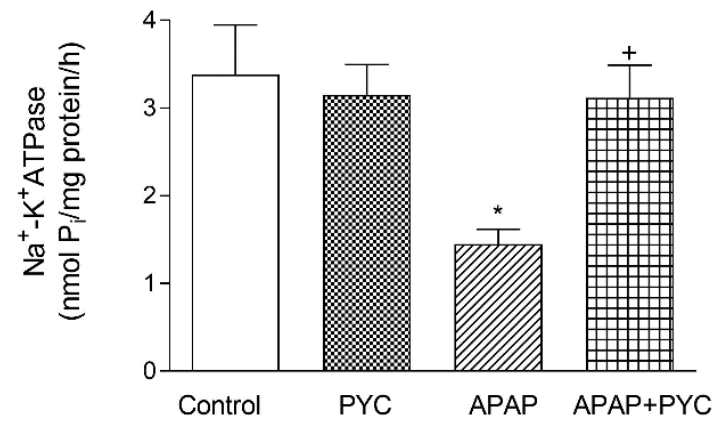

(a)

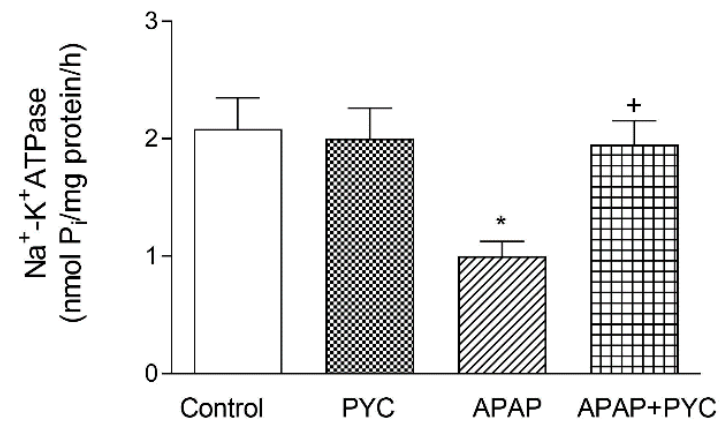

(b)

Figure 5. (a) Hepatic and (b) renal tissue $\mathrm{Na}^{+}-\mathrm{K}^{+}$ATPase activities of the experimental groups. * p<0.05 APAP versus control group; $+\mathrm{p}<0.05$ APAP + PYC versus APAP group. 
In this study, consistent with the histological results, APAP-induced tissue injury results from neutrophil infiltration, possibly due to increased hepatic and renal MPO activities. On the other hand, MPO activities of both tissues are suppressed by PYC administration, which appears to inhibit neutrophil activation, and thus neutrophil related oxidative damage.

$\mathrm{Na}^{+} / \mathrm{K}^{+}$-ATPase is an enzyme attached to cellular membranes and essential in cell viability [53]. Membrane proteins are prone to oxidative changes and alteration in the lipid environment. Since $\mathrm{Na}+\mathrm{K}+-\mathrm{ATPase}$ is a cellular oxidative target, this activity's reduction may be an indirect indicator of oxidative membrane damage [54].
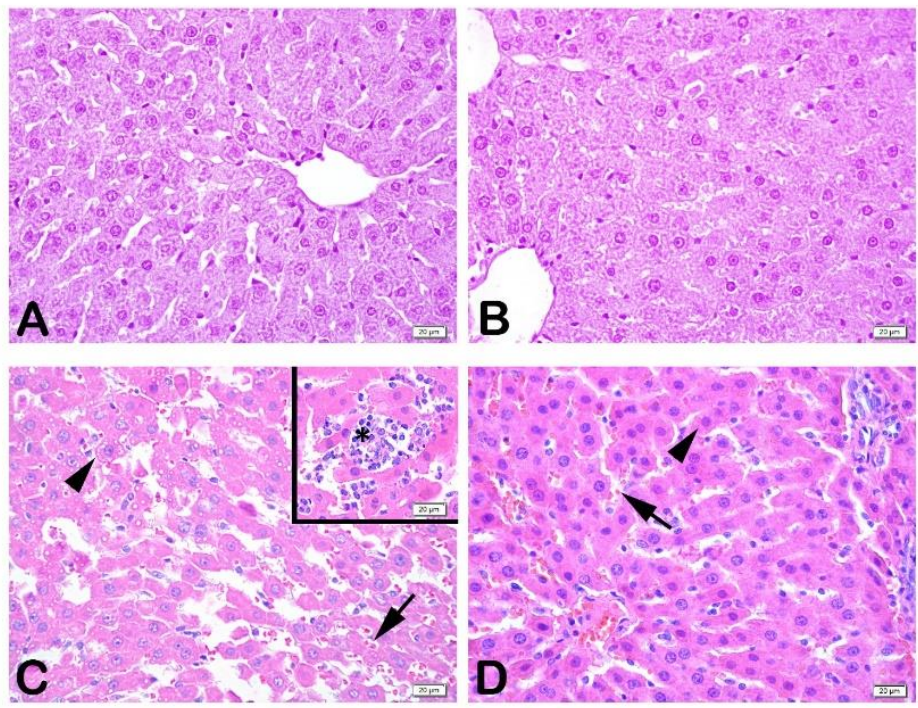

Figure 6. Photomicrographs of rat liver tissues. Control (A) and PYC (B) groups: normal histology of the liver. APAP group (C) has degenerated hepatocytes with many cytoplasmic vacuoles (arrowhead), congestion and sinusoidal dilatation (arrow), and inflammatory cell infiltration (*) in the liver. The APAP+PYC group (D) has a normal appearance of hepatocytes (arrowhead) in most regions and moderate sinusoidal dilatation and vascular congestion (arrow) of the liver (D). H\&E staining, original magnification: 400X, Scale bar: $20 \mu \mathrm{m}$.

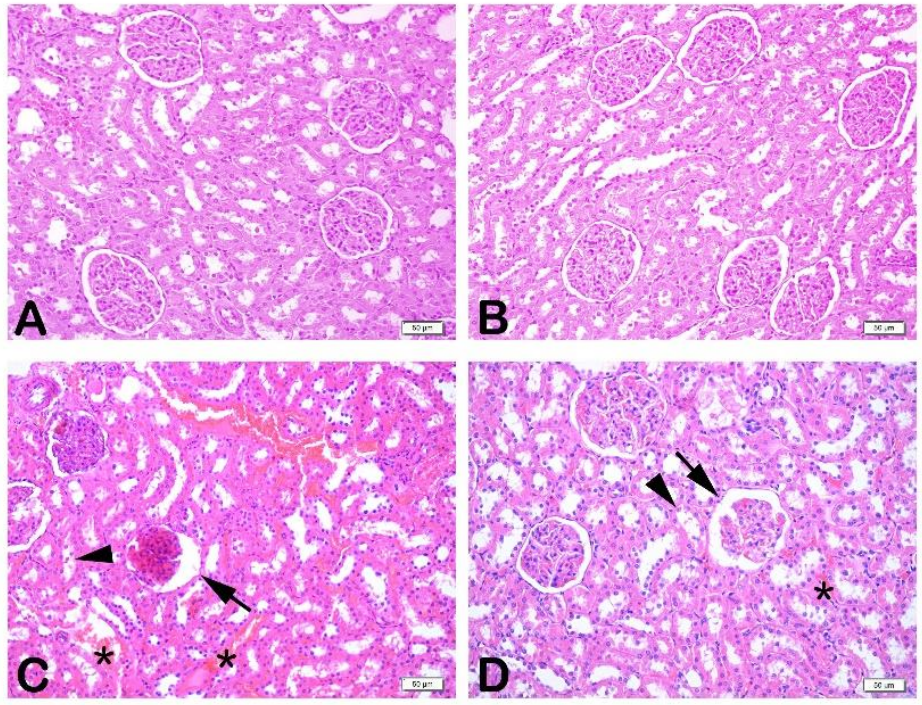

Figure 7. Photomicrographs of rat kidney tissues. Normal histology of kidney in the control (A) and PYC (B). The APAP group (C) has severe glomerular degeneration and dilatation in Bowman space (arrow), tubular cell degeneration (arrowhead), and severe vascular congestion (*) in the kidney. The APAP+PYC group (D) has a generally normal glomerular (arrow) structure, mild tubular cell degeneration (arrowhead), and vascular congestion (*) in most fields of the kidney. H\&E staining, original magnification: 400X, Scale bar: $20 \mu \mathrm{m}$. 
$\mathrm{Na}^{+} / \mathrm{K}^{+}$-ATPase has been reported to be inhibited by reactive oxygen species $[55,56]$. Sehirli et al. (2009) reported that PYC treatment reversed the decreased $\mathrm{Na}^{+} / \mathrm{K}^{+}$-ATPase activity in rats with experimentally induced kidney ischemia [15].

Consistent with these results, in the presented study, $\mathrm{Na}^{+} / \mathrm{K}^{+}$-ATPase activities of the liver and kidney were significantly lower in the APAP group than in the control group. Furthermore, the PYC application in APAP-treated rats caused an increase in enzyme activity, which demonstrates the anti-oxidant and membrane-protective effects of this flavonoid.

Histological assessment of hepatic tissue was found the parenchyma to be normal, with sinusoid structures in control (Figure 6A) and PYC (Figure 6B) groups. In the APAP group (Figure 6C), advanced sinusoidal enlargement and congestion, including damaged hepatocytes with numerous cytoplasmic vacuoles, and observed inflammatory cell infiltration. Mild sinusoidal enlargement and congestion were observed, in addition to hepatocytes exhibiting a relatively normal morphology in the APAP+PYC group (Figure 6D). In the control (Figure 7A) and PYC (Figure 7B) control groups, histological examinations of the renal tissue were found to be normal in terms of glomeruli and tubulous structures, together with the kidney cortex. In the APAP group (Figure 7C), damage to glomeruli and tubulous structures and advanced vascular congestion in the interstitium were inspected. In the APAP-PYC group (Figure 7D), glomerular and tubular damage was reduced, and vascular congestion of the interstitial space was mild.

\section{Conclusions}

In conclusion, PYC treatment corrected the APAP-induced increases in serum proinflammatory cytokines and reversed the impairment in hepatic and renal functions. Besides, higher MDA levels and MPO activity in the hepatic and renal tissues and decline in GSH levels and $\mathrm{Na}^{+} / \mathrm{K}^{+}$-ATPase activity caused by APAP overdose were prevented by PYC treatment. The histological findings also support the protective effect of PYC in hepatorenal injury induced by APAP. From the aforementioned results, PYC is thought to be an effective antiinflammatory and anti-oxidant agent for hepatic and renal tissue protection against the toxic effects of APAP.

\section{Funding}

This research received no external funding.

\section{Acknowledgments}

This research has no acknowledgment.

\section{Conflicts of Interest}

The authors declare no conflict of interest.

\section{References}

1. Jaeschke, H.; Adelusi, O.B.; Akakpo, J.Y.; Nguyen, N.T.; Sanchez-Guerrero, G.; Umbaugh, D.S.; Ding, W.X.; Ramachandran, A. Recommendations for the Use of the Acetaminophen Hepatotoxicity Model for Mechanistic Studies and How to Avoid Common Pitfalls. Acta Pharm. Sin. B 2021, https://doi.org/10.1016/j.apsb.2021.09.023. 
2. Bhushan, B.; Apte, U. Acetaminophen Test Battery (ATB): A Comprehensive Method to Study Acetaminophen-Induced Acute Liver Injury. Gene Expr. 2020, 20, 125-138, https://doi.org/10.3727/105221620X15901763757677.

3. Raevens, S.; Van Campenhout, S.; Debacker, P.-J.; Lefere, S.; Verhelst, X.; Geerts, A.; Van Vlierberghe, H.; Colle, I.; Devisscher, L. Combination of Sivelestat and N-Acetylcysteine Alleviates the Inflammatory Response and Exceeds Standard Treatment for Acetaminophen-Induced Liver Injury. J. Leukoc. Biol. 2020, 107, 341-355, https://doi.org/10.1002/JLB.5A1119-279R.

4. Youdim, K.A.; Joseph, J.A. A Possible Emerging Role of Phytochemicals in Improving Age-Related Neurological Dysfunctions: A Multiplicity of Effects. Free Radic. Biol. Med. 2001, 30, 583-594, https://doi.org/10.1016/s0891-5849(00)00510-4.

5. Ullah, A.; Munir, S.; Badshah, S.L.; Khan, N.; Ghani, L.; Poulson, B.G.; Emwas, A.-H.; Jaremko, M. Important Flavonoids and Their Role as a Therapeutic Agent. Molecules 2020, 25, https://doi.org/10.3390/molecules25225243.

6. Weichmann, F.; Rohdewald, P. Projected Supportive Effects of Pycnogenol(R) in Patients Suffering from Multi-Dimensional Health Impairments after a SARS-CoV2 Infection. Int. J. Antimicrob. Agents 2020, 56, 106191, https://doi.org/10.1016/j.ijantimicag.2020.106191.

7. Malekahmadi, M.; Moradi Moghaddam, O.; Islam, S.M.S.; Tanha, K.; Nematy, M.; Pahlavani, N.; Firouzi, S.; Zali, M.R.; Norouzy, A. Evaluation of the Effects of Pycnogenol (French Maritime Pine Bark Extract) Supplementation on Inflammatory Biomarkers and Nutritional and Clinical Status in Traumatic Brain Injury Patients in an Intensive Care Unit: A Randomized Clinical Trial Protocol. Trials 2020, 21, 162, https://doi.org/10.1186/s13063-019-4008-X.

8. Feng, W.Y.; Tanaka, R.; Inagaki, Y.; Saitoh, Y.; Chang, M.O.; Amet, T.; Yamamoto, N.; Yamaoka, S.; Yoshinaka, Y. Pycnogenol, a Procyanidin-Rich Extract from French Maritime Pine, Inhibits Intracellular Replication of HIV-1 as Well as Its Binding to Host Cells. Jpn. J. Infect. Dis. 2008, 61, 279-285, https://pubmed.ncbi.nlm.nih.gov/18653969/.

9. Marini, A.; Grether-Beck, S.; Jaenicke, T.; Weber, M.; Burki, C.; Formann, P.; Brenden, H.; Schönlau, F.; Krutmann, J. Pycnogenol ${ }^{\circledR}$ Effects on Skin Elasticity and Hydration Coincide with Increased Gene Expressions of Collagen Type I and Hyaluronic Acid Synthase in Women. Skin Pharmacol. Physiol. 2012, 25, 86-92, https://doi.org/10.1159/000335261.

10. Simpson, T.; Kure, C.; Stough, C. Assessing the Efficacy and Mechanisms of Pycnogenol(®) on Cognitive Aging From In Vitro Animal and Human Studies. Front. Pharmacol. 2019, 10, 694, https://doi.org/10.3389/fphar.2019.00694.

11. Schoonees, A.; Visser, J.; Musekiwa, A.; Volmink, J. Pycnogenol® (Extract of French Maritime Pine Bark) for the Treatment of Chronic Disorders. Cochrane database Syst. Rev. 2012, https://doi.org/10.1002/14651858.CD008294.pub4.

12. Huang, W.W.; Yang, J.S.; Lin, C.F.; Ho, W.J.; Lee, M.R. Pycnogenol Induces Differentiation and Apoptosis in Human Promyeloid Leukemia HL-60 Cells. Leuk. Res. 2005, 29, 685-692, https://doi.org/10.1016/j.leukres.2004.10.006.

13. Ramli, N.Z.; Yahaya, M.F.; Tooyama, I.; Damanhuri, H.A. A Mechanistic Evaluation of Anti-oxidant Nutraceuticals on Their Potential against Age-Associated Neurodegenerative Diseases. Anti-oxidants (Basel, Switzerland) 2020, 9, https://doi.org/10.3390/antiox9101019.

14. Grimm, T.; Chovanova, Z.; Muchova, J.; Sumegova, K.; Liptakova, A.; Durackova, Z.; Hogger, P. Inhibition of NF-KappaB Activation and MMP-9 Secretion by Plasma of Human Volunteers after Ingestion of Maritime Pine Bark Extract (Pycnogenol). J. Inflamm. (Lond). 2006, 3, 1, https://doi.org/10.1186/1476-9255-3-1.

15. Sehirli, A.O.; Sener, G.; Ercan, F. Protective Effects of Pycnogenol against Ischemia Reperfusion-Induced Oxidative Renal Injury in Rats. Ren. Fail. 2009, 31, 690-697, https://doi.org/10.3109/08860220903085971.

16. Modlinska, K.; Pisula, W. The Norway Rat, from an Obnoxious Pest to a Laboratory Pet. eLife 2020, 9 , https://doi.org/10.7554/eLife.50651.

17. Sener, G.; Sehirli, O.; Cetinel, S.; Yegen, B.G.; Gedik, N.; Ayanoglu-Dulger, G. Protective Effects of MESNA (2-Mercaptoethane Sulphonate) against Acetaminophen-Induced Hepatorenal Oxidative Damage in Mice. J. Appl. Toxicol. 2005, 25, 20-29, https://doi.org/10.1002/jat.1012.

18. Tekin, S.; Seven, E. Assessment of Serum Catalase, Reduced Glutathione, and Superoxide Dismutase Activities and Malondialdehyde Levels in Keratoconus Patients. Eye 2021, https://doi.org/10.1038/s41433021-01753-1. 
19. Ballatori, N.; Krance, S.M.; Notenboom, S.; Shi, S.; Tieu, K.; Hammond, C.L. Glutathione Dysregulation and the Etiology and Progression of Human Diseases. Biol. Chem. 2009, 390, 191-214, https://doi.org/10.1515/BC.2009.033.

20. Ohkawa, H.; Ohishi, N.; Yagi, K. Assay for Lipid Peroxides in Animal Tissues by Thiobarbituric Acid Reaction. Anal. Biochem. 1979, 95, 351-358, https://doi.org/10.1016/0003-2697(79)90738-3.

21. Beutler, E.; Duron, O.; Kelly, B.M. Improved Method for the Determination of Blood Glutathione. J. Lab. Clin. Med. 1963, 61, 882-888, https://pubmed.ncbi.nlm.nih.gov/13967893/.

22. Chen, S.; Chen, H.; Du, Q.; Shen, J. Targeting Myeloperoxidase (MPO) Mediated Oxidative Stress and Inflammation for Reducing Brain Ischemia Injury: Potential Application of Natural Compounds. Front. Physiol. 2020, 11, 433, https://doi.org/10.3389/fphys.2020.00433.

23. Hillegass, L.M.; Griswold, D.E.; Brickson, B.; Albrightson-Winslow, C. Assessment of Myeloperoxidase Activity in Whole Rat Kidney. J. Pharmacol. Methods 1990, 24, 285-295, https://doi.org/10.1016/01605402(90)90013-b.

24. Özdemir Kumral, Z.N.; Kolgazi, M.; Üstünova, S.; Kasımay Çakır, Ö.; Çevik, Ö.D.; Şener, G.; Yeğen, B. Estrogen Receptor Agonists Alleviate Cardiac and Renal Oxidative Injury in Rats with Renovascular Hypertension. Clin. Exp. Hypertens. 2016, 38, 500-509, https://doi.org/10.3109/10641963.2015.1116550.

25. Lowry, O.H.; Rosebrough, N.J.; Farr, A.L.; Randall, R.J. Protein Measurement with the Folin Phenol Reagent. J. Biol. Chem. 1951, 193, 265-275, https://pubmed.ncbi.nlm.nih.gov/14907713/.

26. Elsayed, A.; Elkomy, A.; Elkammar, R.; Youssef, G.; Abdelhiee, E.Y.; Abdo, W.; Fadl, S.E.; Soliman, A.; Aboubakr, M. Synergistic Protective Effects of Lycopene and N-Acetylcysteine against Cisplatin-Induced Hepatorenal Toxicity in Rats. Sci. Rep. 2021, 11, 13979, https://doi.org/10.1038/s41598-021-93196-7.

27. Liu, J.; Qu, J.; Chen, H.; Ge, P.; Jiang, Y.; Xu, C.; Chen, H.; Shang, D.; Zhang, G. The Pathogenesis of Renal Injury in Obstructive Jaundice: A Review of Underlying Mechanisms, Inducible Agents and Therapeutic Strategies. Pharmacol. Res. 2021, 163, 105311, https://doi.org/10.1016/j.phrs.2020.105311.

28. Forman, H.J.; Zhang, H. Targeting Oxidative Stress in Disease: Promise and Limitations of Anti-oxidant Therapy. Nat. Rev. Drug Discov. 2021, 20, 689-709, https://doi.org/10.1038/s41573-021-00233-1.

29. Liu, H.; Lo, C.R.; Czaja, M.J. NF-KappaB Inhibition Sensitizes Hepatocytes to TNF-Induced Apoptosis through a Sustained Activation of JNK and c-Jun. Hepatology 2002, 35, 772-778, https://doi.org/10.1053/jhep.2002.32534.

30. Chen, C.-J.; Kono, H.; Golenbock, D.; Reed, G.; Akira, S.; Rock, K.L. Identification of a Key Pathway Required for the Sterile Inflammatory Response Triggered by Dying Cells. Nat. Med. 2007, 13, 851-856, https://doi.org/10.1038/nm1603.

31. Cho, K.J.; Yun, C.H.; Packer, L.; Chung, A.S. Inhibition Mechanisms of Bioflavonoids Extracted from the Bark of Pinus Maritima on the Expression of Proinflammatory Cytokines. Ann. N. Y. Acad. Sci. 2001, 928, 141-156, https://doi.org/10.1111/j.1749-6632.2001.tb05644.x.

32. Shu, G.; Qiu, Y.; Hao, J.; Fu, Q.; Deng, X. Gamma-Oryzanol Alleviates Acetaminophen-Induced Liver Injury: Roles of Modulating AMPK/GSK3beta/Nrf2 and NF-KappaB Signaling Pathways. Food Funct. 2019, 10, 6858-6872, https://doi.org/10.1039/c9fo01808e.

33. Yan, M.; Huo, Y.; Yin, S.; Hu, H. Mechanisms of Acetaminophen-Induced Liver Injury and Its Implications for Therapeutic Interventions. Redox Biol. 2018, 17, 274-283, https://doi.org/10.1016/j.redox.2018.04.019.

34. Fan, B.; Dun, S.-H.; Gu, J.-Q.; Guo, Y.; Ikuyama, S. Pycnogenol Attenuates the Release of Proinflammatory Cytokines and Expression of Perilipin 2 in Lipopolysaccharide-Stimulated Microglia in Part via Inhibition of NF-KappaB and AP-1 Activation. PLoS One 2015, 10, e0137837, https://doi.org/10.1371/journal.pone.0137837.

35. Alshahrani, S.; Ashafaq, M.; Hussain, S.; Mohammed, M.; Sultan, M.; Jali, A.M.; Siddiqui, R.; Islam, F. Renoprotective Effects of Cinnamon Oil against APAP-Induced Nephrotoxicity by Ameliorating Oxidative Stress, Apoptosis and Inflammation in Rats. Saudi Pharm. J. 2021, 29, 194-200, https://doi.org/10.1016/j.jsps.2021.01.002.

36. Akakpo, J.Y.; Ramachandran, A.; Orhan, H.; Curry, S.C.; Rumack, B.H.; Jaeschke, H. 4-Methylpyrazole Protects against Acetaminophen-Induced Acute Kidney Injury. Toxicol. Appl. Pharmacol. 2020, 409, 115317, https://doi.org/https://doi.org/10.1016/j.taap.2020.115317.

37. Ramachandran, V.; Raja, B. Protective Effects of Syringic Acid against Acetaminophen-Induced Hepatic Damage in Albino Rats. J. Basic Clin. Physiol. Pharmacol. 2010, 21, 369-385, https://doi.org/10.1515/jbcpp.2010.21.4.369. 
38. Jin, S.E.; Shin, H.-K.; Ha, H. Hepatoprotective Effects of Gamisoyo-San against Acetaminophen-Induced Liver Injuries. Integr. Med. Res. 2021, 10, 100466, https://doi.org/10.1016/j.imr.2020.100466.

39. Matuz-Mares, D.; Riveros-Rosas, H.; Vilchis-Landeros, M.M.; Vázquez-Meza, H. Glutathione Participation in the Prevention of Cardiovascular Diseases. Antioxidants , 2021, 10, https://doi.org/10.3390/antiox10081220.

40. Vairetti, M.; Di Pasqua, L.G.; Cagna, M.; Richelmi, P.; Ferrigno, A.; Berardo, C. Changes in Glutathione Content in Liver Diseases: An Update. Antioxidants (Basel, Switzerland) 2021, 10, https://doi.org/10.3390/antiox10030364.

41. Michaut, A.; Moreau, C.; Robin, M.-A.; Fromenty, B. Acetaminophen-Induced Liver Injury in Obesity and Nonalcoholic Fatty Liver Disease. Liver Int. Off. J. Int. Assoc. Study Liver 2014, 34, e171-9, https://doi.org/10.1111/liv.12514.

42. Güvenç, M.; Cellat, M.; Gökçek, İ.; Özkan, H.; Arkalı, G.; Yakan, A.; Yurdagül Özsoy, Ş.; Aksakal, M. Nobiletin Attenuates Acetaminophen-Induced Hepatorenal Toxicity in Rats. J. Biochem. Mol. Toxicol. 2020, 34, https://doi.org/10.1002/jbt.22427.

43. De Mel, J.U.; Gupta, S.; Harmon, S.; Stingaciu, L.; Roth, E.W.; Siebenbuerger, M.; Bleuel, M.; Schneider, G.J. Acetaminophen Interactions with Phospholipid Vesicles Induced Changes in Morphology and Lipid Dynamics. Langmuir 2021, 37, 9560-9570, https://doi.org/10.1021/acs.langmuir.1c01458.

44. Sayiner, S.; Gulmez, N.; Sabit, Z.; Gulmez, M. Effects of Deep-Frying Sunflower Oil on Sperm Parameters in A Mouse Model: Do Probiotics Have A Protective Effect? Kafkas Univ. Vet. Fak. Derg. 2019, 1-7, https://doi.org/10.9775/kvfd.2019.22063.

45. Virgili, F.; Kobuchi, H.; Packer, L. Procyanidins Extracted from Pinus Maritima (Pycnogenol): Scavengers of Free Radical Species and Modulators of Nitrogen Monoxide Metabolism in Activated Murine RAW 264.7 Macrophages. Free Radic. Biol. Med. 1998, 24, 1120-1129, https://doi.org/10.1016/s0891-5849(97)004309.

46. Ansari, M.A.; Keller, J.N.; Scheff, S.W. Protective Effect of Pycnogenol in Human Neuroblastoma SH-SY5Y Cells Following Acrolein-Induced Cytotoxicity. Free Radic. Biol. Med. 2008, 45, 1510-1519, https://doi.org/10.1016/j.freeradbiomed.2008.08.025.

47. Maritim, A.; Dene, B.A.; Sanders, R.A.; Watkins, J.B. 3rd. Effects of Pycnogenol Treatment on Oxidative Stress in Streptozotocin-Induced Diabetic Rats. J. Biochem. Mol. Toxicol. 2003, 17, 193-199, https://doi.org/10.1002/jbt.10078.

48. Siler-Marsiglio, K.I.; Paiva, M.; Madorsky, I.; Serrano, Y.; Neeley, A.; Heaton, M.B. Protective Mechanisms of Pycnogenol in Ethanol-Insulted Cerebellar Granule Cells. J. Neurobiol. 2004, 61, 267-276, https://doi.org/10.1002/neu.20057.

49. Çolak, R.; Celik, A.; Diniz, G.; Alkan Özdemir, S.; Yilmaz, O.; Calkavur, S. Evaluation of the Neuroprotective Effect of Pycnogenol in a Hypoxic-Ischemic Brain Injury Model in Newborn Rats. Am. J. Perinatol. 2021, https://doi.org/10.1055/s-0041-1730349.

50. Pérez-Figueroa, E.; Álvarez-Carrasco, P.; Ortega, E.; Maldonado-Bernal, C. Neutrophils: Many Ways to Die. Front. Immunol. 2021, 12, 631821, https://doi.org/10.3389/fimmu.2021.631821.

51. Özkan, E.; Akyüz, C.; Dulundu, E.; Topaloglu, Ü.; Şehirli, A.Ö.; Ercan, F.; Şener, G. Protective Effects of Lycopene on Cerulein-Induced Experimental Acute Pancreatitis in Rats. J. Surg. Res. 2012, 176, 232-238, https://doi.org/10.1016/j.jss.2011.09.005.

52. Arnhold, J. The Dual Role of Myeloperoxidase in Immune Response. Int. J. Mol. Sci., 2020, 21, 8057, https://doi.org/10.3390/ijms21218057.

53. Thomas, C.E.; Reed, D.J. Radical-Induced Inactivation of Kidney Na+,K(+)-ATPase: Sensitivity to Membrane Lipid Peroxidation and the Protective Effect of Vitamin E. Arch. Biochem. Biophys. 1990, 281, 96-105, https://doi.org/10.1016/0003-9861(90)90418-x.

54. Rose, A.M.; Valdes, R.J. Understanding the Sodium Pump and Its Relevance to Disease. Clin. Chem. 1994, 40, 1674-1685, https://pubmed.ncbi.nlm.nih.gov/8070076/.

55. Bejček, J.; Spiwok, V.; Kmoníčková, E.; Rimpelová, S. Na(+)/K(+)-ATPase Revisited: On Its Mechanism of Action, Role in Cancer, and Activity Modulation. Molecules 2021, 26, 1905, https://doi.org/10.3390/molecules26071905.

56. Qu, X.; Zhang, Z.; Hu, W.; Lou, M.; Zhai, B.; Mei, S.; Hu, Z.; Zhang, L.; Liu, D.; Liu, Z.; Chen, J.; Wang, Y. Attenuation of the Na/K-ATPase/Src/ROS Amplification Signaling Pathway by Astaxanthin Ameliorates Myocardial Cell Oxidative Stress Injury. Mol. Med. Rep. 2020, 22, 5125-5134, https://doi.org/10.3892/mmr.2020.11613. 